\title{
Predictive value of cerebrospinal fluid lactate for the diagnosis and treatment efficacy of post- neurosurgery bacterial meningitis
}

\section{Yufang Wang}

Sun Yat-sen University First Affiliated Hospital

Jingchao Li

Sun Yat-sen University First Affiliated Hospital

Mingli Yao

Sun Yat-sen University First Affiliated Hospital

Lingyan Wang

Sun Yat-sen University First Affiliated Hospital

Bin Ouyang ( $\nabla$ binouyang888@163.com )

Sun Yat-sen University First Affiliated Hospital

Research article

Keywords: CSF lactate, Bacterial meningitis, Post-neurosurgery, Diagnosis, Treatment efficacy

Posted Date: December 10th, 2019

DOl: https://doi.org/10.21203/rs.2.18481/v1

License: (c) (1) This work is licensed under a Creative Commons Attribution 4.0 International License.

Read Full License 


\section{Abstract}

Background: Post-neurosurgical bacterial meningitis (PNBM) is a severe complication with high morbidity and mortality. Rapid and accurate diagnosis of PNBM is difficult. Therefore, it is necessary to find more reliable markers to assist the diagnosis. This study aims to evaluate the predictive value of cerebrospinal fluid (CSF) lactate for PNBM diagnosis and treatment efficacy.

Methods: Total 105 cases were enrolled in patients with clinically suspected PNBM who underwent neurosurgeries during October 2015 to December 2016. CSF lactate as well as CSF routine and biochemistry test was measured. Receivers operating characteristic (ROC) curve analysis was used to evaluate the diagnostie power of CSF lactate for PNBM. To assess the predictive value of CSF lactate for treatment efficacy, a linear regression was used and tendency diagrams of CSF lactate and glucose for each patient were drawn.

Results: Fifty-four of 105 patients were diagnosed with PNBM. CSF lactate level was significantly higher in PNBM than in non-PNBM patients $(p<0.001)$. The ROC curve analysis showed a great diagnostic power of CSF lactate for PNBM, and the cut-off value was $4.15 \mathrm{mmol} / \mathrm{L}$ (AUC $=0.92$, sensitivity, 92.6\%; specificity, 74.5\%). The combination of CSF lactate and glucose showed better diagnostic efficacy (AUC = 0.97 , sensitivity, $94.4 \%$; specificity, $90.2 \%$ ). The linear regression showed that $\triangle \mathrm{CSF}$ lactate inversely correlated with $\triangle C S F$ glucose and directly correlated with $\triangle C S F$ leucocyte (both $p<0.001$ ). The tendency diagrams showed CSF lactate a better predictor for PNBM treatment efficacy than CSF glucose.

Conclusion: Our study showed CSF lactate had an excellent discriminatory power in distinguishing between PNBM and non-PNBM. The combination of CSF lactate and glucose had a better diagnostic accuracy than other CSF parameters alone. CSF lactate was a reliable predictor of treatment efficacy in PNBM patients.

\section{Background}

Post-neurosurgical bacterial meningitis (PNBM) is a severe post-surgical complication with high morbidity and mortality ${ }^{1,2}$. To reduce morbidity and mortality, it is crucial to rapidly diagnose and timely initiate appropriate antimicrobial therapy and adjunctive dexamethasone therapy ${ }^{3 \otimes 4}$. However, rapid and accurate diagnosis of PNBM is difficult, because of the unspecific clinical symptoms and CSF parameters. Moreover, bacterial culture results are with very low detection rate (reported to be about 6$\left.9 \%^{5}\right)$, and take days to get results, making it less helpful in early accurate diagnosis. Therefore, it is necessary to find more reliable biochemical markers with high sensitivity and specificity, presenting in early course of infections, to assist in rapid diagnosis of PNBM. According to 2017 IDSA guideline for healthcare-associated ventriculitis and meningitis ${ }^{6}$, an elevated CSF lactate may be useful in the diagnosis of healthcare-associated bacterial ventriculitis and meningitis, but there is no clear cut-off value of CSF lactate for PNBM diagnosis. To monitor the response to treatment, CSF analysis is very necessary. However, without identified culture result, there is no evidence which CSF parameter is more 
reliable for the treatment response. Therefore, we conducted this study to further evaluate the diagnostic value of CSF lactate for PNBM and predictive value for treatment efficacy.

\section{Methods}

\section{Patients}

This study was conducted between October 2015 and December 2016 at the First affiliated Hospital of Sun Yat-sen University. Patients who underwent neurosurgery and hospitalized in a10-bed neurosurgical ICU were screened. Lumbar punctures were performed to collect cerebrospinal fluid samples in clinically suspected PNBM patients who presented clinical symptoms of fever, headache, neck stiffness, and unexplained neurological deterioration. CSF biochemistry included: gram stain and culture, white and red blood cell counts, as well as protein, glucose and lactate levels. The diagnosis of post neurosurgical bacterial meningitis was accorded to the criteria of $\mathrm{CDC} / \mathrm{NHSN} 2008^{7}$ \at least 1 of the following criteria should be met: (1) Patient has organisms cultured from CSF. (2) Organisms from CSF were visualized by gram stain. (3) At least 1 of the following signs or symptoms with no other recognized $\nabla f$ ever $\left(>38^{\circ} \mathrm{C}\right)$, headache, stiff neck, meningeal signs, cranial nerve signs, irritability, or altered consciousness level, combined with at least 1 of the testing results: increased white cells $\left(>10 \times 10^{6} / \mathrm{L}\right)$, elevated protein $(>600$ $\mathrm{mg} / \mathrm{L})$, and/or decreased glucose $(<2.4 \mathrm{mmol} / \mathrm{L}$ or the ratio of CSF glucose to blood glucose was lower than 0.4 ) in CSF. Patients who did not meet the above criteria were classified into the non-PNBM group. Patients under antibiotic therapy for other infections were excluded (patients with perioperative prophylactic antibiotics were not excluded). The Ethics Committee of the First Affiliated Hospital of Sun Yat-sen University approved this study. Prior written informed consent was obtained from each patient.

\section{Measurements}

After CSF samples were collected, following CSF and peripheral blood tests were performed: CSF leucocyte count, CSF protein, CSF glucose, CSF lactate, CSF Gram stain, CSF bacterial cultures, blood lactate, blood WBC, serum procalcitonin (PCT), and C-reactive protein (CRP). CSF lactate level and synchronous blood-gas analysis for blood lactate were performed within 5 minutes after sampling. Other CSF tests were carried out within 2 hours of sampling. All blood tests were performed on the same day by the central laboratory.

To learn the evaluation value of CSF lactate for antibiotic treatment efficacy, there were eight patients were being taking CSF samples and measuring the CSF parameters not only for diagnosis, but also 2 or more times after the initiation of antibiotic treatment. We calculated the variability of CSF lactate, glucose and leucocytes, by CSF parameters values taking after treatment minus the first value taking for diagnosis (expressing as $\triangle \mathrm{CSF}$ lactate, $\triangle \mathrm{CSF}$ glucose and $\triangle \mathrm{CSF}$ leucocytes), the correlation between $\Delta C S F$ lactate and $\triangle C S F$ glucose and leucocytes were assessed. 


\section{Statistical analysis}

The continuous variables were expressed as mean \pm standard deviation (Mean \pm SD). The categorical variables were expressed as case number and percentage. Continuous variables were analyzed using Student's independent t-test between non-PNBM and PNBM groups, if normality was not assumed, Wilcoxon rank-sum test would be used instead. The categorical results between groups were tested using Chi-square test or Fisher's exact test (if any expected value $<5$ was observed). Normality assumption was tested using Shapiro-Wilk test. Crude and adjusted logistic regression models were used to investigate the associations between independent variables to PNBM, the variables which were significant in both crude and adjusted results would be recognized as associated variables. Receivers operating characteristic (ROC) curves were applied to evaluate discriminatory power of each CSF marker. An ideal cut-off would be suggested by comparatively maximum Youden's index among coordinates. Pearson's correlation coefficient analysis was used to assess the relations among the change of CSF parameters. A p-value under than 0.05 would be recognized as reaching significance of each test, two-tailed. All analyses were performed using IBM SPSS Version 20 (SPSS Statistics V20, IBM Corporation, Somers, New York).

\section{Results}

CSF samples were obtained from 105 suspected PNBM cases. Following the above-mentioned clinical criteria, 54 patients were diagnosed as PNBM (51.4\%\%), and 51 patients were in no-PNBM group (48.6\%). Demographic data are shown in Table 1. Seventy-three patients were males (69.5\%) and overall mean age was 55.14 ( \pm 11.11 years). Most common surgical procedures were hematoma evacuation (36 patients, $34.29 \%$ ) and ventriculoperitoneal shunt (26 patients, $24.76 \%$ ), significant difference of neurosurgeries was observed $(p<0.001)$. Emergency surgery was defined as a life-threatening neurosurgical condition, which required an urgent neurosurgery to prevent further deterioration and/or death, including hematoma evacuation, decompressive craniectomy and external ventricular drainage, which was performed in 78 patients $(76.47 \%)$, but there was no significant difference between the two groups $(p=0.283)$. No significant difference was found in patient's age and gender (both $p>0.05)$.

CSF samples were obtained from all enrolled patients to perform gram stainings and bacteria cultures. However, there were only 5 positive cultures in all 54 PNBM cases $(9.3 \%)$, and no positive gram stain. The isolated microorganisms were Acinetobacter baumannii ( 2 cases), Escherichia coli (1 case), Enterococcus faecalis (1 case) and staphylococcus heamolyticus (1 case). In this study, all patients received routine antibiotic prophylaxis before and after neurosurgery following hospital guidelines.

CSF parameters were listed in Table 2. Mean CSF lactate was significantly higher in PNBM group than those in no-PNBM group $(6.45 \mathrm{mmol} / \mathrm{L}$ vs. $3.21 \mathrm{mmol} / \mathrm{L} ; \mathrm{p}<0.001 ; \mathrm{Fig} .1)$. CSF leucocyte count and protein levels were significantly higher in PNBM group $(p<0.001)$. Inversely, CSF glucose level and CSF:blood glucose ratio were lower in PNBM group $(p<0.001)$. 
The blood biomarkers of WBC, PCT, CRP and lactate were also collected and showed in Table 3. There were no significant differences between non-PNBM group and PNBM group in all of the four parameters ( $p=0.134,0.108,0.473$ and 0.990 , respectively).

To further investigate the association of independent variables to PNBM, the crude and adjusted logistic regression models were used, adjusted model was controlled with patient's age, gender, neurosurgeries, and CSF-RBC. The variables which were significant in both crude and adjusted results would be recognized as associated factors to PNBM. As indicated in Table 4, the parameters including leucocytes, protein, glucose, CSF:blood glucose ratio, and lactate in CSF were all significant in both crude and adjusted results (all $p<0.05)$.

The results of ROC curve analysis of CSF and serum markers mentioned above were shown in Table 5 and Fig. 2. To distinguishing between non-PNBM and PNBM, CSF protein and lactate demonstrated more excellent discriminatory power (AUC $=0.896$ and 0.882 , sensitivity over $80 \%$; specificity almost reaches $80 \%$ ) than other traditional CSF markers. The cut-off values all parameters were suggested by comparatively maximum Youden's index, e.g., lactate was $4.15 \mathrm{mmol} / \mathrm{L}$ (Table 5). When CSF lactate combined with glucose, it showed the best diagnostic efficacy (AUC $=0.954$, sensitivity, $89 \%$; specificity, 90\%). Comparatively, CSF lactate had better AUC, sensitivity, specificity, PLR, and NLR than glucose, which means that CSF lactate might possess better diagnostic effectiveness than CSF glucose.

We collected multiple CSF samples in the treatment course of eight PNBM patients, and the tendency diagram of CSF lactate and glucose levels for each patient was drawn (Fig. 3). It showed that the tendency of CSF lactate level was opposite to CSF glucose level in the whole treatment course (except the first patient), meaning when CSF glucose level went up, the CSF lactate level went down. So CSF lactate level can be a predictor for treatment efficacy. To further explore the predictive value of CSF lactate for treatment efficacy, the $\triangle C S F$ lactate and $\triangle C S F$ glucose and leucocytes were calculated. Correlation coefficient analysis was used to assess the evaluation value of CSF lactate for antibiotic treatment efficacy. It demonstrated that $\Delta$ CSF lactate inversely correlated with $\Delta$ CSF glucose $(r=-1.07 ; p<0.001$; $95 \% \mathrm{Cl}:-1.57$ to -0.58$)$, but directly correlated with CSF leucocyte $(r=0.0008 ; p<0.001 ; 95 \% \mathrm{Cl}$ : 0.0005 to 0.0011).

\section{Discussion}

The diagnosis of PNBM was always depend on unspecific clinical symptoms and conventional CSF laboratory biomarkers, including gram stain, bacterial culture, leucocyte count, protein and glucose in $\mathrm{CSF}^{7,8}$. Clinical characteristics of bacterial meningitis include fever, headache, nuchal rigidity, and change in mental status, but not all the patients with bacterial meningitis present these symptoms. In patients with bacterial meningitis, the proportion of classic triad of fever, nuchal rigidity and change in mental status was only $44.4 \%{ }^{9}$. Furthermore, patients post-neurosurgery may present with fever and neck stiffness not because of bacterial meningitis, but because of aseptic meningitis ${ }^{10}$. Consequently, the clinical symptoms had very low diagnostic accuracy. At the same time, there were many factors to 
influence the CSF leucocyte count, protein and glucose, making them unspecific for bacterial meningitis. Blood contamination of CSF can lead to the elevation of CSF leucocyte count and protein level ${ }^{11}$, which was very common in post-neurosurgical patients due to the original diseases (such as hemorrhage, subarachnoid hemorrhage), surgeries and local injuries of lumbar punctures. CSF glucose level changed resulting from choroid epithelium function as well as bacterial pathogens and leucocytes ${ }^{12}$. So besides bacterial infection, many factors could lead to decreased level of CSF glucose, including blood glucose ${ }^{12}$, blood-stained ${ }^{13}$, meningeal disseases ${ }^{14}$, long-time exposure to air. Furthermore, post-neurosurgical inflammatory response can be seen due to the stimulation of blood, dust bone, implant material, sloughing tissue, surgical manipulation and so on囚in which the CSF profiles are similar to those in bacterial meningitis ${ }^{15}$. As the golden diagnostic standard of bacterial meningitis, CSF bacterial cultures remain very low positive rate, reported only about $10 \%$ or even lower ${ }^{16,17}$ and it takes up to days for organism identification. Gram stain can permit a rapid and accurate recognition of causative pathogen in $60 \%-90 \%$ of patients with community-acquired bacterial meningitis, and it has a specificity of $97 \% 8$. However, the likelihood of visualizing the bacterium on Gram stain, correlates with the CSF concentration of bacteria ${ }^{18}$, techniques ${ }^{19}$, specific bacterial pathogen causing meningitis ${ }^{20}$. And more important, Same as bacterial cultures, prior antimicrobial therapy reduces the positive rate of gram stain ${ }^{8,21}$. Therefore the conventional laboratory biomarkers are not reliable in rapid accurate diagnosis of PNBM.

There are several sources that CSF lactate originating from. Brain tissue, including neurons and glia, is the main source ${ }^{22}$. In bacterial meningitis, the whole brain is with edema leading to a reduction of global cerebral blood flow. And inflammatory situation involves the vasculature with loss of autoregulatory mechanisms, vasospasms, and thrombosis ${ }^{23-25}$. These lead to cerebral ischemia and anaerobic metabolism. Bacterial pathogens themselves produce about $10 \%$ of total CSF lactate in patients with $\mathrm{BM}^{16}$. In addition, cytokines due to the inflammatory situation in brain reduce tissue oxygen uptake and cause an increasement of anaerobic metabolism, thus increasing lactate production ${ }^{22}$. Neutrophils invading into the subarachnoid space also contribute to the rise in CSF lactate level by glycolysis ${ }^{26}$. In addition, it was proven that lactate penetrates the blood-brain barrier at a very low rate, and CSF lactate are not affected by the systemic lactate ${ }^{27,28}$. As showed in our study, even though there was significant difference of lactate in CSF between PNBM and non-PNBM patients $(p<0.001)$, the serum lactate was not significantly different between groups $(p=0.561)$. This made CSF lactate a more reliable index presenting the cerebral metabolism.

Some previous studies proved CSF lactate as a useful biomarker in diagnosing bacterial meningitis. Sakushima et al. ${ }^{29}$ performed a meta-analysis including 33 studies with 1885 patients, confirming the excellent diagnostic value of CSF lactate for differentiating bacterial meningitis from aseptic meningitis. Later, there were studies focused on the diagnostic accuracy of CSF lactate in PNBM ${ }^{6,17,30}$. The cut-off values were ranging from $3.45-5.4 \mathrm{mmol} / \mathrm{L}$. Similarly, Our study showed that the CSF lactate had better diagnostic power for PNBM than conventional CSF markers. Sensitivity and Specificity were $92.6 \%$ and $74.5 \%$ respectively, with cut-off value of $4.15 \mathrm{mmol} / \mathrm{L}$. But the specificity of the CSF lactate as well as 
positive likelihood ration (PLR) and negative predictive value (NPV) were not powerful enough for the accurate diagnosis of PNBM. Therefore, we combined CSF lactate and CSF glucose. The ROC curve analysis showed the combination of CSF lactate and CSF glucose demonstrated a much more higher diagnostic accuracy compared with other CSF markers alone (AUC $=0.97$; sensitivity, $94.5 \%$; specificity, 90.2\%). For all the potential PNBM patients with a CSF lactate level higher than the diagnostic threshold, the percent of actual PNBM patients was reflected by the PPV. Although the CSF lactate has a great PPV of $90.5 \%$, a higher PPV of $93.9 \%$ was achieved when CSF lactate combined with CSF glucose, indicating that this method is even better suited to accurately diagnose PNBM. Similarly, for all the potential nonPNBM patients with a CSF lactate level lower than the diagnostic threshold, the percent of actual nonPNBM patients was reflected by the NPV. The combination of CSF lactate and CSF has a higher PPV of 91.1\% than CSF lactate alone, indicating that this test method is also more suitable to discriminate the non-PNBM patients. Because PLR and NLR were not affected by the morbidity, they can be used to evaluate the diagnostic test more effectively. A higher PLR and a lower NPV indicate a better diagnostic efficacy. Although CSF lactate showed a relatively high PLR and a low NLR, the results showed the combined CSF lactate and glucose had a more favorable PLR and NLR compared to lactate alone. According to our results, the CSF lactate showed a good efficacy for PNBM diagnosis, and when combined with CSF glucose, it achieved a very excellent diagnostic efficacy.

As reported, treatment efficacy of PNBM was evaluated by both clinical and bacteriologic responses to therapy ${ }^{31}$, and the treatment duration was unclear ${ }^{32}$. Even though, there was a consensus on the treatment duration of common community-acquired bacterial meningitis based more on experience than evidence $^{32,33}$, there was not any solid or reliable experience or evidence for the treatment duration of hospital-acquired or post-neurosurgical bacterial meningitis. Due to the very low detection rate of bacterial culture, in clinical practice, we can only depend on clinical response and changing of CSF leucocyte count and CSF glucose level to evaluate the treatment efficacy and to determine the treatment duration. It was proven that CSF glucose was useful for monitoring treatment efficacy ${ }^{34}$. Our study showed that the changing trend of CSF lactate was inversely correlated with $\triangle$ CSF glucose $(p<0.001)$, and directly correlated with $\triangle$ CSF leucocyte $(p<0.001)$, which suggested that CSF lactate was a detector for the treatment efficacy of PNBM. Meanwhile, the tendency diagrams of CSF lactate and glucose for each patient were drawn (Fig. 3). It demonstrated the similar results that the tendency of CSF lactate level was opposite to CSF glucose level in the whole treatment course, meaning CSF lactate was as sensitive as CSF glucose for the treatment efficacy. The tendency diagrams demonstrated that CSF lactate was more favorable to monitor patients' response to treatment than CSF glucose. In patients with short treatment course (patients No.1 to 4), the changing trends of CSF glucose and lactate were synchronous and consistent. In patients with long disease courses, the CSF lactate showed some advantages. First, when patients' situation improved (patients No.5 to 7), the CSF lactate showed a smooth decreasing curve while the CSF glucose fluctuated. So the tendency of CSF lactate represented the patients' response better than CSF glucose. Second, in No. 8 patient, there was a second infection in CSF during the therapeutic course of meningitis, namely super-infection ${ }^{35}$. In the first infection, bacterial culture was negative, and when the patient's situation turned down, Acinetobacter baumannii was cultured in CSF. 
The CSF lactate rose steeply, while the CSF glucose dropped a little, which was ambiguous for assessing treatment efficacy. So when the infection was uncontrolled or even got worse, CSF lactate could give us a much obvious hint than glucose, and may be clue for a second infection and consideration of altering treatment regimen.

Other new biomarkers, such as procalcitonin $(\mathrm{PCT})^{36}, \mathrm{C}$-reactive protein (CRP) ${ }^{37}, \mathrm{sCD} 163^{38}$, or the heparin-binding protein ${ }^{39}$, were proposed to try to distinguish between bacterial and aseptic meningitis. Procalcitonin, as an ideal marker for a variety of bacterial infections, eg respiratory tract infections, acute infectious endocarditis and pancreatitis, allows an early diagnosis and facilitate therapeutic decisions ${ }^{40}$. And previous studies proved that serum PCT had high diagnostic accuracy for diagnosing bacterial meningitis ${ }^{41-43}$. However, it failed to get a consensus on diagnostic value of CSF PCT. Jereb et al. showed that CSF PCT was also a good marker for diagnosis of bacterial meningitis ${ }^{43}$, while Shimetani et al. demonstrated the CSF PCT did not differ in different meningitis ${ }^{41}$. When it comes to PNBM, CSF PCT may help a little in diagnosis with relatively low sensitivity (68\%) and specitivity $(73 \%)^{6}$, while serum PCT showed no help at all ${ }^{44}$. As the same, our study demonstrated that there was no significant difference in serum PCT between PNBM and non-PNBM $(p=0.409)$. CRP is an acute-phase reactant, and CRP level measurements are frequently used to aid in the diagnosis of bacterial infections ${ }^{37}$. CRP is synthesized by the liver, mainly in response to $\mathrm{IL}-6$, which is produced not only during infection but also in many types of inflammation ${ }^{45}$. Even though it was proven that CRP was a detector of bacterial meningitis in children, in our study, there was no significant difference of CRP between PNBM and non-PNBM $(p=0.074)$. So our study demonstrated that the common serum markers for bacterial infection, including white blood cell count, PCT and CRP, helped little in the diagnosis of PNBM.

To our knowledge, this was the first study to assess the evaluation value of CSF lactate for PNBM treatment efficacy. This area should be studied further more in future. Nevertheless, the study has several limitations. First, there were only eight patients for evaluation value of CSF lactate for antibiotic treatment efficacy. Since, the sample size was small, no further statistic analysis was performed. Second, the diagnostic criteria we used to discriminate PNBM from non-PNBM were based on the criteria of CDC/NHSN 2008, but the actual diagnosis was mainly dependent on clinical characteristics and CSF leucocyte count, glucose and protein due to low detective rate of pathogen tests.

\section{Conclusions}

In conclusion, our study showed that CSF lactate had an excellent discriminatory power with high sensitivity and acceptable specificity in distinguishing between PNBM and non-PNBM, even though all the enrolled patients were under prophylactic antibiotic treatment. The combination of CSF lactate and CSF glucose had better diagnostic accuracy than other CSF parameters alone. Furthermore, CSF lactate was a reliable detector of treatment efficacy in PNBM patients.

\section{List Of Abbreviations}


PNBM: Post-neurosurgical bacterial meningitis; PCT: procalcitonin; CRP: C-reactive protein; ROC:

Receivers operating characteristic; PLR: positive likelihood ration; NPV: negative predictive value; PCT: procalcitonin; CRP: C-reactive protein

\section{Declarations}

Ethics approval and consent to participate

The Ethics Committee of the First Affiliated Hospital of Sun Yat-sen University approved this study. Prior written informed consent was obtained from each patient.

\section{Consent for publication}

A written informed consent was obtained from the patient for publication of this case report and any accompanying images.

Availability of data and materials

All the data and material were presented in the main paper.

Competing interests

The authors declare that they have no competing interests.

\section{Funding}

This study is supported by the Natural Science Foundation of Guangdong Province (2018A030313589).

\section{Authors' contributions}

We declare that all the listed authors have participated actively in the study and all meet the requirements of the authorship. BO designed the study and wrote the protocol, YF and JL acquired data, MY analyzed the data. YW and LW undertook the statistical analysis, YF and was a major contributor in writing the manuscript. All authors read and approved the final manuscript.

\section{Acknowledgements}

None declared.

\section{References}

1.National Nosocomial Infections Surveillance System. National Nosocomial Infections Surveillance (NNIS) System Report, data summary from January 1992 through June 2004, issued October 2004. Am J Infect Control. 2004;32:470-85. 
2.Sharma MS, Vohra A, Thomas P, Kapil A, Suri A, Chandra PS, et al. Effect of risk-stratified, protocolbased perioperative chemoprophylaxis on nosocomial infection rates in a series of 31927 consecutive neurosurgical procedures (1994-2006). Neurosurgery. 2009;64:1123-31.

3.Ziai WC, Lewin JJ 3rd. Update in the diagnosis and management of central nervous system infections. Neurol Clin. 2008;26:427-68.

4.Aronin SI, Peduzzi P, Quagliarello VJ. Community-acquired bacterial meningitis: risk stratification for adverse clinical outcome and effect of antibiotic timing. Ann Intern Med. 1998;129:862-9.

5.Li Y, Zhang G, Ma R, Du Y, Zhang L, Li F, et al. The diagnostic value of cerebrospinal fluids procalcitonin and lactate for the differential diagnosis of post-neurosurgical bacterial meningitis and aseptic meningitis. Clin Biochem. 2015;48:50-4.

6. Tunkel AR, Husbun R, Bhimraj A, Byers K, Kaplan SL, Scheld WM, et al. 2017 Infectious Diseases Society of America's Clinical Practice Guidelines for Healthcare-Associated Ventriculitis and Meningitis. Clin Infect Dis. 2017;64:e34-65.

7.Horan TC, Andrus M, Dudeck MA. CDC/NHSN surveillance definition of health care-associated infection and criteria for specific types of infections in the acute care setting. Am J Infect Control. 2008;36:309-32.

8.Tunkel AR, Hartman BJ, Kaplan SL, Kaufman BA, Roos KL, Scheld WM, et al. Practice guidelines for the management of bacterial meningitis. Clin Infect Dis. 2004;29:1267-84.

9.Van de Beek D, De Gans J, Spanjaard L, Weisfelt M, Reitsma JB, Vermeulen M. Clinical features and prognostic factors in adults with bacterial meningitis. N Engl J Med. 2004;351:1849-59.

10.Ross D, Rosegay H, Pons V. Differentiation of aseptic and bacterial meningitis in postoperative neurosurgical patients. J Neurosurg. 1988;69:669-74.

11.Jerrard DA, Hanna ER, Schindelheim GL. cerebrospinal fluid. J Emerg Med. 2001;21:171-8.

12.Watson MA, Scott MG. Clinical utility of biochemical analysis of cerebrospinal fluid. Clin Chem. 1995;41:343-60.

13.Begovac J, Baće A, Soldo I, Lehpamer B. Lactate and glucose in cerebrospinal fluid heavily contaminated with blood. Acta Med Croatica. 1991;45:341-5.

14.Fishman RA. Carrier transport and the concentration of glucose in cerebrospinal fluid in meningeal diseases. Ann Intern Med. 1965;63:153-5.

15.Forgacs $\mathrm{P}$, Geyer CA, Freidberg SR. Characterization of chemical meningitis after neurological surgery. Clin Infect Dis. 2001;32:179-85. 
16.Salord F, Boussaid O, Eynard N, Perret C, Grando J, Chacornac R. Value of D(-) lactate determination for the fast diagnosis of meningitis after craniotomy (in French). Ann Fr Anesth Reanim. 1994;13:64753.

17.Leib SL, Boscacci R, Gratzl O. Predictive value of cerebrospinal fluid (CSF) lactate level versus CSF/Blood glucose ratio for the diagnosis of bacterial meningitis following neurosurgery. Clin Infect Dis. 1999;29:69-74.

18.La Scolea LJ Jr, Dryja D. Quantitation of bacteria in cerebrospinal fluid and blood of children with meningitis and its diagnostic significance. J Clin Microbiol. 1984;19:187-90.

19.Chapin-Robertson K, Dahlberg SE, Edberg SC. Clinical and laboratory analyses of cytospin-prepared Gram stains for recovery and diagnosis of bacteria from sterile body fluids. J Clin Microbiol. 1992;30:377-80.

20.Gray LD, Fedorko DP. Laboratory diagnosis of bacterial meningitis. Clin Microbiol Rev. 1992;5:130-45.

21.Simon TD, Pope CE, Browd SR, Ojemann JG, Riva-Cambrin J, Mayer-Hamblett N, et al. Evaluation of microbial bacterial and fungal diversity in cerebrospinal fluid shunt infection. PLoS ONE. 2014;9:e83229.

22.Tureen J. Effect of recombinant human tumor necrosis factor-alpha on cerebral oxygen uptake, cerebrospinal fluid lactate, and cerebral blood flow in the rabbit: role of nitric oxide. J Clin Invest. 1995;95:1086-91.

23.Leib SL, Kim YS, Chow LL, Sheldon RA, Täuber MG. Reactive oxygen intermediates contribute to necrotic and apoptotic neuronal injury in an infant rat model of bacterial meningitis due to group $B$ streptococci. J Clin Invest. 1996;98:2632-9.

24.Leib SL, Kim YS, Black SM, Tureen JH, Täuber MG. Inducible nitric oxide synthase and the effect of aminoguanidine in experimental neonatal meningitis. J Infect Dis. 1998;177:692-700.

25.Nau R, Brück W. Neuronal injury in bacterial meningitis: mechanisms and implications for therapy. Trends Neurosci. 2002;25:38-45.

26.Täuber MG, Borschberg U, Sande MA. Influence of granulocytes on brain edema, intracranial pressure, and cerebrospinal fluid concentrations of lactate and protein in experimental meningitis. J Infect Dis. 1988;157:456-64.

27.Guerra-Romero L, Täauber MG, Fournier MA, Tureen JH. Lactate and glucose concentrations in brain interstitial fluid, cerebrospinal fluid, and serum during experimental pneumococcal meningitis. J Infect Dis. 1992;166:546-50.

28.Cameron PD, Boyce JM, Ansari BM. Cerebrospinal fluid lactate in meningitis and meningococcaemia. J Infect. 1993;26:245-52. 
29.Sakushima K, Hayashino Y, Kawaguchi T, Jackson JL, Fukuhara S. Diagnostic accuracy of cerebrospinal fluid lactate for differentiating bacterial meningitis from aseptic meningitis: A metaanalysis. J Infect. 2011;62:255-62.

30.Maskin LP, Capparelli F, Mora A, Hlavnicka A, Orellana N, Díaz MF, et al. Cerebrospinal fluid lactate in post-neurosurgical bacterial meningitis diagnosis. Clin Neurol Neurosurg. 2013;115:1820-5.

31.Wang JH, Lin PC, Chou $\mathrm{CH}$, Ho CM, Lin $\mathrm{KH}$, Tsai CT, et al. Intraventricular antimicrobial therapy in postneurosurgical Gram-negative bacillary meningitis or ventriculitis: A hospital-based retrospective study. J Microbiol Immunol Infect. 2014;47:204-10.

32.Radetsky M. Duration of treatment in bacterial meningitis: a historical inquiry. Pediatr Infect Dis J. 1990;9:2-9.

33.Patricia O. How long to treat bacterial meningitis. Lancet. 1993;341:530-7.

34.Bonadio WA. The cerebrospinal fluid: physiologic aspects and alterations associated with bacterial meningitis. Pediatr Infect Dis J. 1992;11:423-31.

35.Huang CR, Chen SF, Lu CH, Chuang YC, Tsai NW, Chang CC, et al. Clinical characteristics and therapeutic outcomes of nosocomial super-infection in adult bacterial meningitis. BMC Infect Dis. 2011;11:133.

36.Vikse J, Henry BM, Roy J, Ramakrishnan PK, Tomaszewski KA, Walocha JA. The role of serum procalcitonin in the diagnosis of bacterial meningitis in adults: a systematic review and meta-analysis. Int J Infect Dis. 2015;38:68-76.

37.Peltola H, Valmari P. Serum C-reactive protein as detector of pretreated childhood bacterial meningitis. Neurology. 1985;35:251-3.

38.Knudsen TB, Larsen K, Kristiansen TB, Møller HJ, Tvede M, Eugen-Olsen J, et al. Diagnostic value of soluble CD163 serum levels in patients suspected of meningitis: comparison with CRP and procalcitonin. Scand J Infect Dis. 2007;39:542-53.

39.Linder A, Akesson P, Brink M, Studahl M, Björck L, Christensson B. Heparin-binding protein: a diagnostic marker of acute bacterial meningitis. Crit Care Med. 2011;39:812-7.

40.Christ-Crain M, Müller B. Procalcitonin in bacterial infections-hype, hope, more or less? Swiss Med Wkly. 2005;135:451-60.

41.Shimetani N, Shimetani K, Mori M. Levels of three inflammation markers, C-reactive protein, serum amyloid A protein and procalcitonin, in the serum and cerebrospinal fluid of patients with meningitis. Scand J Clin Lab Invest. 2009;61:567-74. 
42.Abdelkader NA, Mahmoud WA, Saber SM. Serum procalcitonin in Egyptian patients with acute meningitis and a negative direct cerebrospinal fluid examination. J Infect Public Health. 2014;7:106-13.

43.Jereb M, Muzlovic I, Hojker S, Strle F. Predictive value of serum and cerebrospinal fluid procalcitonin levels for the diagnosis of bacterial meningitis. Infection 2001;29:209-12.

44.Choi SH, Choi SH. Predictive performance of serum procalcitonin for the diagnosis of bacterial meningitis after neurosurgery. Infect Chemother. 2013;45:308-14.

45.Ridker PM. Clinical application of C-reactive protein for cardiovascular disease detection and prevention. Circulation. 2003;107:363-9.

\section{Tables}

\section{Table 1. Baseline Characteristics of Randomized Patients}

\begin{tabular}{|c|c|c|c|c|}
\hline & $\begin{array}{l}\text { All patients } \\
(\mathrm{n}=105)\end{array}$ & $\begin{array}{l}\text { Non-PNBM } \\
(\mathrm{n}=51)\end{array}$ & $\begin{array}{l}\text { PNBM } \\
(\mathrm{n}=54)\end{array}$ & $\mathbf{P}$ \\
\hline Age (mean $\pm \mathrm{SD})$ & \multicolumn{4}{|c|}{$55.14 \pm 11.1154 .18 \pm 12.1456 .06 \pm 10.060 .110$} \\
\hline Gender & & & & 0.297 \\
\hline Male & $73(69.52)$ & $33(64.71)$ & $40(74.07)$ & \\
\hline Female & $32(30.48)$ & $18(35.29)$ & $14(25.93)$ & \\
\hline Neurosurgeries & & & & $<0.001$ \\
\hline $\begin{array}{l}\text { Craniostomy for brain } \\
\text { tumor }\end{array}$ & $18(17.14)$ & $14(27.45)$ & $4(7.41)$ & \\
\hline Hematoma evacuation & $36(34.29)$ & $17(33.33)$ & $19(35.19)$ & \\
\hline $\begin{array}{l}\text { Decompressive } \\
\text { craniectomy }\end{array}$ & $16(15.24)$ & $4(7.84)$ & $12(22.22)$ & \\
\hline Ventriculoperitoneal shu & t26 (24.76) & $16(31.37)$ & $10(18.52)$ & \\
\hline $\begin{array}{l}\text { External ventricular } \\
\text { drainage }\end{array}$ & $9(8.57)$ & $0(0.00)$ & $9(16.67)$ & \\
\hline Emergency procedures & $78(76.47)$ & $39(81.25)$ & $39(72.22)$ & 0.283 \\
\hline
\end{tabular}




\section{Table 2. Cerebrospinal fluid parameters results.}

\begin{tabular}{lllll}
\hline & $\begin{array}{l}\text { All patients } \\
(\mathrm{n}=105)\end{array}$ & $\begin{array}{l}\text { Non-PNBM } \\
(\mathrm{n}=51)\end{array}$ & $\begin{array}{l}\text { PNBM } \\
(\mathrm{n}=54)\end{array}$ & $\mathrm{P}$ \\
\hline CSF leucocytes $\left(10^{6} / \mathrm{L}\right)$ & $543.27 \pm 1352.12$ & $99.65 \pm 144.27$ & $962.24 \pm 1788.75$ & $<0.001$ \\
\hline CSF proteins $(\mathrm{mg} / \mathrm{L})$ & $8305.78 \pm 15154.23$ & $2111.12 \pm 2047.58$ & $14156.29 \pm 19361.83<0.001$ \\
\hline CSF glucose (mmol/L) & $3.23 \pm 1.62$ & $4.14 \pm 1.52$ & $2.37 \pm 1.20$ & $<0.001$ \\
\hline CSF:blood glucose ratio $0.37 \pm 0.19$ & $0.46 \pm 0.15$ & $0.30 \pm 0.18$ & $<0.001$ \\
\hline CSF lactate (mmol/L) & $4.88 \pm 2.51$ & $3.21 \pm 1.34$ & $6.45 \pm 2.33$ & $<0.001$ \\
\hline CSF-RBC & & & & 0.916 \\
\hline 0 & $23(21.90)$ & $12(23.53)$ & $11(20.37)$ & \\
\hline $1+$ & $26(24.76)$ & $11(21.57)$ & $15(27.78)$ & \\
\hline $2+$ & $15(14.29)$ & $8(15.69)$ & $7(12.96)$ & \\
\hline $3+$ & $17(16.19)$ & $9(17.65)$ & $8(14.81)$ & \\
\hline $4+$ & $24(22.86)$ & $11(21.57)$ & $13(24.07)$ & \\
\hline
\end{tabular}

Table 3. Blood parameters results.

\begin{tabular}{lllll}
\hline & $\begin{array}{l}\text { All patients } \\
(\mathrm{n}=105)\end{array}$ & Non-PNBM & PNBM & \\
& & & \\
& & & \\
WBC & $11.56 \pm 4.44$ & $10.89 \pm 3.66$ & $12.20 \pm 5.01$ & 0.134 \\
CRP & $48.32 \pm 55.60$ & $37.98 \pm 43.39$ & $58.09 \pm 63.94$ & 0.108 \\
PCT & $0.51 \pm 0.94$ & $0.83 \pm 1.31$ & $0.25 \pm 0.28$ & 0.473 \\
Lac & $1.54 \pm 1.06$ & $1.72 \pm 1.38$ & $1.38 \pm 0.61$ & 0.990 \\
\hline
\end{tabular}


Abbreviation: WBC, white blood cell; CRP, C-reactive protein; PCT, procalcitonin; Lac, lactate.

Table 4. Crude and adjusted logistic regression results of independent variables to PNBM

\begin{tabular}{|c|c|c|c|c|}
\hline \multirow[b]{2}{*}{ Parameters } & \multicolumn{2}{|l|}{ Crude } & \multicolumn{2}{|l|}{ Adjusted } \\
\hline & OR (95\% CI) & $\mathrm{P}$ & OR (95\% CI) & $\mathrm{P}$ \\
\hline \multicolumn{5}{|l|}{$C S F$} \\
\hline Leucocytes & $1.00(1.00-1.01)$ & $<0.001$ & $1.01(1.00-1.01)$ & $<0.001$ \\
\hline Protein & $1.00(1.00-1.00)$ & $<0.001$ & $1.001(1.00-1.001)$ & $<0.001$ \\
\hline Glucose & $0.31(0.18-0.51)$ & $<0.001$ & $0.17(0.08-0.37)$ & $<0.001$ \\
\hline CSF:blood glucose ratio & $0.00(0.00-0.04)$ & $<0.001$ & $0.00(0.00-0.01)$ & $<0.001$ \\
\hline Lactate & $2.47(1.77-3.44)$ & $<0.001$ & $9.63(3.07-30.23)$ & $<0.001$ \\
\hline \multicolumn{5}{|l|}{ Serum } \\
\hline WBC & $1.07(0.98-1.17)$ & 0.135 & & \\
\hline CRP & $1.01(1.00-1.01)$ & 0.070 & & \\
\hline PCT & $0.35(0.12-0.96)$ & 0.041 & $0.30(0.08-1.06)$ & 0.062 \\
\hline Lactate & $0.73(0.48-1.09)$ & 0.123 & & \\
\hline
\end{tabular}

The adjusted model were controlled with patient's age, gender, diagnosis, and CSF-RBC.

Table 5. The diagnostic power of CSF markers to distinguish between non-PNBM and PNBM. 


\begin{tabular}{|c|c|c|c|c|c|c|c|c|}
\hline & AUC & $\begin{array}{l}\text { Cut-off } \\
\text { value }\end{array}$ & $\begin{array}{l}\text { Sensitivity } \\
(\%)\end{array}$ & $\begin{array}{l}\text { Specificity } \\
(\%)\end{array}$ & PLR & NLR & $\begin{array}{l}\text { PPV } \\
(\%)\end{array}$ & $\begin{array}{l}\text { NPV } \\
(\%)\end{array}$ \\
\hline CSF leucocytes $\left(10^{6} / \mathrm{L}\right)$ & 0.753 & 231.5 & 0.54 & 0.90 & 5.48 & 0.51 & 0.85 & 0.65 \\
\hline CSF protein $(\mathrm{mg} / \mathrm{L})$ & 0.896 & 2050.7 & 0.94 & 0.75 & 3.71 & 0.07 & 0.80 & 0.93 \\
\hline CSF glucose (mmol/L) & 0.822 & 3.15 & 0.74 & 0.75 & 2.91 & 0.35 & 0.75 & 0.73 \\
\hline $\begin{array}{l}\text { CSF:blood glucose } \\
\text { ratio }\end{array}$ & 0.776 & 0.33 & 0.59 & 0.86 & 4.32 & 0.47 & 0.82 & 0.67 \\
\hline CSF lactate $(\mathrm{mmol} / \mathrm{L})$ & 0.882 & 4.15 & 0.85 & 0.76 & 3.62 & 0.19 & 0.79 & 0.83 \\
\hline $\begin{array}{l}\text { CSF glucose + CSF } \\
\text { lactate (estimated } \\
\text { probability) }\end{array}$ & 0.954 & 0.49 & 0.89 & 0.90 & 9.07 & 0.12 & 0.91 & 0.88 \\
\hline $\begin{array}{l}\text { CSF/blood glucose } \\
\text { ratio + CSF lactate } \\
\text { (estimated probability) }\end{array}$ & 0.882 & 0.34 & 0.89 & 0.73 & 3.24 & 0.15 & 0.77 & 0.86 \\
\hline
\end{tabular}

Abbreviation: AUC, area under the curve; PLR, positive likelihood ratio; NLP, negative likelihood ratio; PPV, positive predictive value; NPV, negative predictive value. 